\section{Changing Educational Needs for Research, Teaching, and Extension ${ }^{1}$}

\section{R. KEITH ARNOLD}

Deputy Chief for Research, Forest Service, U.S. Department of Agriculture, Washington, D.C.

\section{Highlight}

To unlock the complicated interrelationships of the range, scientific and managerial talents of the highest order are needed. This paper suggests goals for range management education and proposes one strategy for achieving these goals in the universities. The appropriate faculty can provide strong training for range professionals and meet the general education needs of the university community and other professionals as well.

Range management, along with many other professions, is entering a new and exciting era. That era

${ }^{1}$ Presented at the annual meeting of the American Society of Range Management, Denver, Colorado, February 1970. Accepted for publication March 28, 1970. may well be characterized by the name "Quality of the Environment." The 1970's are already characterized as the "Environmental Decade," ushered in by President Nixon in his State of the Union message on January 22, 1970. There are three overriding precepts which set the stage for us in considering the new and exciting era:

1. There is the increasing public concern about man's global environment. Every turn of the radio or TV dial, nearly every printed page reveals that man's concern about his environment is really the question "Can man exist for long on earth?"

2. Of particular concern to us is the fact that the conservation movement is broadening from preoccupation with minerals, wildlife, and wilderness to an awareness of the whole balance of nature and the total environment of man.

3. Despite our awareness and concern and even some beginnings of action, our environment continues to deteriorate. Pollution, degradation, and destruction of natural ecosystems and natural beauty are proceeding faster than corrective counter-measurcs. Man's tcchnology, his capacity for modifying the environment, has been and is increasing faster than his knowledge of its impacts on the environment.

The Forest Service is now sharpening its concepts, studying new approaches, and employing new techniques to look at the problems of management and protection of our rangelands. And the key to satisfactory solutions to these problems is analysis of the total ecosystemincluding trade-offs between environmental concerns and productivity concerns. 
As we approach our job of studying, managing, and protecting the range, we find the analysis of ecosystems involves many familiar and traditional features. We have long recognized the multiple values of range resources and the complexity of their intcracting factors. There are, however, facets of the job that are new or now have greater importance.

In the past, we studied and worked with the rangelands with a central emphasis on maximizing livestock production. Our treatments never strayed too far from the optimum for livestock production. We're still going to work with livestock. But rather than isolating grazing as a part of the total ecosystem, we'll extend the boundaries of our research to find what interdependencies are important. We're going to measure the responses to grazing management in terms of livestock production. But we're also going to measure those responses in terms of other goods and services-water, timber, fish, wildlife, etc. In essence, we'll study the entire complex system.

How or why, you might wonder, did we come to adopt this approach? Research has brought us here in part. We have learned to think increasingly of cause-and-effect phenomena, not in terms of two simple variables but, in systems. Computers and technology of sufficient sophistication to handle problems of our complex ccosystems have become available.

I would like to pause here to relate the complexity of our problems of managing range ecosystem with the complexity of the prob lems which placed a man on the moon. Computers were able to monitor completely all the plans, all the crises, and all the alternative actions, and to have solutions ready to use in a micro-second's time. I doubt if the computer exists that could store such information about plans, operations, and alternatives for the world's ecosystems. It can ccrtainly handlc major parts of it, but not the entire problem. And, of course, not the entire solution. Furthermore, basic understanding of the long- and short-range changes going on in the soil, plant, air interaction-the effects of pollution; possible effects of weather modification; effects of intensive management over time-just isn't available.

To unlock the complicated interrelationships of the range-including plants, animals, environment, and people - we need scientific and managerial talent of the highest order. The demands on and opportunities for educational programs are unprecedented.

At the outset, I emphasize that we do not expect our scientists and managers to become systems analysts. Although the techniques of systems analysis are implicit in our approach to research, we would prefer to hire analysts to render support services to our scientists.

The analysis of our major ecosystems will require an interdisciplinary team of expert researchers having a variety of knowledge and skills. The team is needed because of the complexity of our systems and the unique manner in which different disciplines view the same ecosystem. Members of this research team must have a thorough and modern knowledge of one or more of the basic sciences, broad working knowledge of each other's field, and an awareness of the capabilities of the powerful economic and statistical tools that are available. And I hasten to add-the proper balance of the liberal arts and humanities.

The undergraduate education of a range manager must continue to be flexible. The baccalaureate may be followed by graduate study for careers in science or education or immediate employment in resource management or livestock production on privately owned ranches. The individual student chooses among these alternative careers in the latter part of or often after his undergraduate education. And he may switch to another alternative after a few years of employment.
Regardless of his choice of careers, the range manager must be given a broader education. He cannot practice his chosen profession adequately unless he understands the relationship of the range to the total environment and the interrelated, often conflicting, desires of the range users. His background should include survey courses in wildlife, watershed, forest, and recreation management. Or existing range courses may be modified to include these uses-emphasizing the unity of the range resource rather than the diversity of range uses. To increase this interdisciplinary orientation of students, traditional organization lines within the universities must give way.

Greater breadth of education should not be achieved at the expense of liberal arts and the basic sciences. These, too, need strengthening. But, we should reexamine range curricula that still require such courses as poultry and dairy husbandry, horticulture, and field crops. Such courses are too distantly related to the native ranges and their multiple products.

Greater emphasis must be placed on principles and concepts of the basic sciences and less on the technology of range management. If well versed in the basic sciences, the student can readily assimilate and use the technology of range management. He can grow with new technology and ensure his professional stature.

Let's stop right here! I am falling into the trap of outsiders trying to tell the professional educators how to do the very thing the educators alone know best. May we back off now, and identify some goals for range management education, list some of the problems which universities face in achieving these goals, and suggest one strategy for achieving them.

Until recently, I was directly involved in developing educational programs at the University of Michigan for the rapidly changing fields of natural resources management. 
I have also had the opportunity to be a member of the FAO International Committee on Forestry Education and to serve as consultant to a number of universities on Natural Resources Programs. Consequently, I appreciate the magnitude of this task and more critically, the question, "Is there a place for Range Management in today's and tomorrow's university?"

I would like to suggest four goals for range management education, and I would hasten to add that these goals are not unique to the field of range management. They certainly apply to other natural resource areas and probably to every professional field taught in universities. First, a university education should provide a sense of relevance -in our case the relevance of range management to man's continued existence on this earth.

By sense of relevance, we also create a sense of the importance of range management to mankind, and its importance for the production of beef and for the creation and maintenance of a quality environment.

The second goal is a sense of urgency. Range management is, has always been, a long-time proposition. We have had time to take five, ten, even twenty years to work out new grazing systems, new forms of management. But in this decade of environmental quality, if we do not produce in universities those who can consult and advise on policy and those who can relate range management to the rest of man's activities, the range manager will become a high level technician under those who have cither achieved the broader role or who have assumed it by default.

The third goal is that of interdisciplinary communication. Range managers must interact, day by day, with all other resource managers. This communication has been traditional. But today's world also requires communications among natural scientists, social scientists, and engineers. If such communications and interactions do not start in the universities, they will never be satisfactory for the real world problems.

The fourth and last goal I would like to identify is the capacity and motivation to learn. In the past, those of us in education have been more concerned with what should be in the curriculum rather than with creating the ability to continue to learn after graduation. It is physically and mentally impossible to provide course work which covers everything that a range manager should know. The argument about a 4-year curriculum versus a 5-year curriculum is spuriousneither one is sufficient. In effect, we suggest a life-long curriculum in which a man learns how to learn in a university and has enough professional background in his chosen discipline to allow him to earn his pay on the first job he gets. This goal not only suggests an increasing capability and motivation to learn on the part of the individual, it also requires continuing educational programs in the universities.

It is important that we recognize the problems which universities face as they create the institution, the organization, the educational system if you will, to achieve these goals. There are certain characteristics intrinsic to the university as an institution which must be recognized. For example, there are weak incentives for interdisciplinary teaching as well as interdisciplinary research. Recognition in terms of promotion and salary is largely based on publication in professional journals and on creative graduate instruction leading to successful Ph.D's. The discipline-oriented department or professionally oriented department is the traditional university structure provided for the group of discipline or professionally oriented educators. Departments are not structured for interdisciplinary communication. Social scientists and engineers are rarely made at home or even made to feel at home in a natural resource department. These departments have no peer group at hand to evaluate their professional and teaching progress. The student has a broader challenge than the faculty! This entire problem area is complicated further by the vigor with which freedom of research interest is regarded by the academic community-and rightly so. It is only recently that universities have sensed the nature of this problem and are working to create new institutions to meet it head on.

In terms of range management, I believe part of the answer lies in a wide variety of curricula and of organization in universities to meet the need for range managers.

I don't propose to know the answer or even to know the one best approach. I would like to suggest one strategy which may be profitable for several universities to follow. This strategy also eliminates the question which every university president faces-can he afford a given program or professional school or professional department. In this day of rising costs, universities are looking with a critical eye at the costs involved in small professional curricula. In terms of range management, the question often is, Can this university really use some of its scarce resources to teach professional range management? I suggest we turn the question around to read like this-Can a university-or can this university really afford not to have the educational and research resources required to educate outstanding professionals in the field of range management?

The tactics required go something like this: For a university to meet the general educational requirements and specialized professional requirements in all fields critically concerned with the quality of the environment, there must be available on the campus professors with knowledge of systems ecology, soils, hydrology, resource economics, and other disciplines directly contributing to range management. Since cellular biologists have largely captured the teaching and research in botany and zoology 
in universities, the natural resource field now provides the best home for those rather basic scientists concerned with the growth, development, and maintenance of animals, plants, and man in ecosystems. The professional staff of the range-environment unit provides service courses on the natural environment to the general university community. Other highly specialized courses are given for other profes- sions such as law, engineering, public health, and medicine.

If this faculty is selected with care, it can meet the needs I have described for the general education of the university community and other professions. It will also have that combination of individual professional strengths which provides the strongest possible professional training in the light of the four goals already identified. Some of you may feel that this suggestion deemphasizes the profession of range management. I would argue, on the contrary, that this kind of an educational strategy will guarantee not only the continuation of professional range management education, but it will allow it to develop and enlarge its position of leadership so critically needed in over one-half of the area of the United States. 